\title{
O SISTEMA DE SOLUÇÃO DE CONTROVÉRSIAS DO MERCOSUL E SUA INFLUÊNCIA PARA O PROCESSO DE INTEGRAÇÃO
}

Everton Luis Hirt ${ }^{1}$

\section{RESUMO}

A formação dos blocos econômicos exige dos Estados a diminuição do seu grau de liberdade em favor do bem comum do bloco. No entanto, a igualdade entre os Estados só é alcançado com a institucionalização do bloco, que ocorre a partir de um sistema eficiente de solução de controvérsias. No caso do Mercosul, primeiro tivemos a criação de um Tribunal Arbitral Ad Hoc e posteriormente a criação de um Tribunal Permanente. Este foi criado não só para dar maior efetividade ao processo de integração, mas também para se adequar a uma tendência mundial e ter maior prestígio no palco internacional.

\section{ABSTRACT}

The formation of the economic blocks demands that States reduce their degree of freedom in favor of the common wealth of the block. However the equality among the States is only reached with the institutionalization of the block what occurs from an efficient system of solution of controversies. In the case of the Mercosur, first we had the creation of an Ad Hoc Arbitrational Court and, later, the creation of a Permanent Court. This last one was created not only to arise the effectiveness to the integration process, but also in order to be adjusted to a world-wide trend and to have greater prestige in the international scene.

Palavras chaves: Mercosul, sistema de solução de controvérsias, soberania.

Key words: Mercosur, system of solution of controversies, sovereignty.

\footnotetext{
${ }^{1}$ Graduado em Relações Internacionais pela Universidade Tuiutí do Paraná e integrante do Núcleo de Estudos em Direito Internacional da Universidade Federal do Paraná.
}

Revista Brasileira de Direito Internacional, Curitiba, v.2, n.2, jul./dez.2005 


\section{INTRODUÇÃO}

As novas configurações das relações internacionais exigem que os Estados emitam respostas rápidas no mundo globalizado. Uma delas é a formação de blocos econômicos para a manutenção do seu espaço nos mercados regionais e ampliação da competitividade internacional. Não obstante, a associação em blocos exige dos Estados o cumprimentos de normas comuns, que muitas vezes vão de encontro com o interesse nacional. A formação do Mercosul não foi diferente, pois se trata de uma região onde a lei da soberania absoluta ainda impera, principalmente por que foi em uma região marcada pelos conflitos fronteiriços.

Dessa forma, o presente trabalho vem procurar entender como que se deu a evolução do sistema de solução de controvérsias do Mercosul. Em um primeiro momento, farei um esboço do conceito de soberania, que é ponto crucial no que toca os Estados mercosulinos. Em um segundo momento, demonstrarei a evolução do sistema de solução de controvérsias do Mercosul, a partir da apresentação dos tratados, protocolos e as suas influências.

\section{DO CONCEITO CLÁSSICO DE SOBERANIA A} SUPRANACIONALIDADE

O conceito clássico de soberania surge, na visão aristotélica, com a concepção de que o homem não nasceu para viver em sociedade. Na visão de Rousseau, os homens são livres e iguais. Ele também coloca o conceito de "sociedades parciais" que nasce do conflito de interesses com o Estado, que por sua vez representa a vontade geral ${ }^{2}$.

$\mathrm{Na}$ concepção maquiavélica o Estado é toda a entidade que exerce domínio sobre homens. Para Hegel o Estado é tido como absoluto. Para Del Vecchio o Estado é a entidade de ordem jurídica que torna comum a vida de um povo. Marx e Engels, voltados para uma concepção sociológica, afirmam que o Estado é algo que nem sempre existiu e nem sempre existirá. Para 
Weber o Estado é o detentor do poder coercitivo da força física e/ou material ${ }^{3}$. Para Smend:

\begin{abstract}
"o Estado atual é incessante luta de integração. Reflete, na sua estrutura, forças independentes que congrega e comanda. É um ângulo de convergência de todas as forças sociais propulsoras, sob sua disciplina, da felicidade e da ordem, no seio da comunhão. Ausculta as tendências, as influências dos fenômenos da natureza, imprimindo-lhes rumo e ritmo dirigidos à sua finalidade geral" ${ }^{1}$.
\end{abstract}

O conceito de soberania estatal tem surgimento com o Tratado de Westfália, que através do direito internacional, tornou os Estados independentes, soberanos e iguais por fiat jurídico, o que consolidou a teoria clássica de soberania ${ }^{5}$. Thomas Robbis, em seu livro Leviatã, coloca que o Estado surge do conflito de interesses entre os indivíduos, em uma luta de todos contra todos, onde o homem é o lobo do homem, e para que esses não se destruam eles sedem a sua soberania em favor de uma entidade superior, 0 Estado, que passará a reger a vida destes.

Do ponto de vista jurídico o Estado tinha como objetivo efetivar seu poder em seu território sem deixar que um outro Estado interfira neste poder ou na sua efetividade. $\mathrm{Na}$ forma clássica a soberania é inalienável, onde os Estados seriam capazes de tudo para a sua manutenção. Não obstante, no mundo globalizado esse conceito de soberania já não cabe mais. A integração internacional, com relacionamento intergovernamentais, integração para diminuir os conflitos regionais, interdependência e a constante mutação do cenário internacional, faz com que o conceito de soberania seja repensado.

A busca incessante de novos mercado e ampliação na participação do sistema mundial, para a sobrevivência dos Estados, fazem com que haja a construção de uma soberania supranacional. Nesta questão o conceito clássico de soberania, criado pelo direito internacional, é suprimido pela noção de

\footnotetext{
${ }^{2}$ FURLAN, Fernando de Magalhães. Integração e Soberania: o Brasil e o Mercosul, 2004, pp. 17

${ }^{3}$ FURLAN, Fernando de Magalhães. Integração e Soberania: o Brasil e o Mercosul, 2004, pp. 17-18

${ }^{4}$ FURLAN, Fernando de Magalhães. Integração e Soberania: o Brasil e o Mercosul, 2004, pp. 19.

${ }^{5}$ FURLAN, Fernando de Magalhães. Integração e Soberania: o Brasil e o Mercosul, 2004, pp. $19-20$.
}

Revista Brasileira de Direito Internacional, Curitiba, v.2, n.2, jul./dez.2005 
interdependência, baseado em uma ótica econômica. Neste novo conceito, a soberania deixa de ser indivisível, onde são cedidas competências aos órgãos supranacionais $^{6}$. Dessa forma é possível termos uma soberania coletiva, pois ao mesmo tempo em que o Estado é soberano para delegar competências a um órgão supranacional, pois acredita que ele trará melhores resultados do que a sua atuação independente, ele ainda é soberano para se retirar de uma entidade supranacional no momento que lhe convir.

Apesar dessa tendência de integração um dos maiores problemas para a efetivação desse processo de integração ainda é a sujeição do Estado às normas internacionais, o que vai de encontro com a teoria clássica de soberania. Na maioria das vezes se permite que o órgão supranacional atue nos pontos onde o Estado tem debilidade, mas evita-se a constituição de um poder supremo e total sobre o Estado. Não obstante, a necessidades do mundo globalizado "o próprio Estado, por um ato de soberania, aceita por meio da assinatura de um tratado se sujeitar à jurisdição internacional e, em face dos princípios clássicos do Direito Internacional Público (pacta sunt servanda e reciprocidade), deverá cumprir as normas decorrentes do tratado". 7

No entanto, para o processo de integração do Mercosul a questão de soberania, não só para os Estados-Membros, mas de forma geral para a América do Latina, é um tema de grande sensibilidade devido os processo históricos, que vem da rivalidade entre Espanha e Portugal para a dominação dos mares. Apesar da Argentina e o Paraguai terem um maior ideal para construir entidades supranacionais para o Mercosul, Brasil e Uruguai sempre buscam deixá-las em proporções confiáveis.

\section{MONISMO E DUALISMO}

As duas teorias que tem como concepção o contexto jurídico interno são de suma importância para saber como os Estados trabalham com o direito

\footnotetext{
${ }^{6}$ BRANCO, Luizella Giardino B. Sistema de soluções de controvérsias no Mercosul, 1997, pp. 28.

${ }^{7}$ GOMES, Eduardo B. Protocolo de Olivos: alterações no sistema de solução de controvérsias do Mercosul e perspectivas, 2003, pp. 80.
}

Revista Brasileira de Direito Internacional, Curitiba, v.2, n.2, jul./dez.2005 
interno e o direito internacional. Dessa forma se faz necessário distingui-las para entendermos como ela atingi o conceito de soberania.

A teoria monista acredita que os ordenamentos jurídicos, interno e internacional, são distintos e não podem ser confundidos como um único ordenamento. No entanto, existe uma relação entre eles, onde podemos encontrar três fases: a primeira que acredita que o direito interno prevalece sobre o internacional; a segunda que o direito internacional prevalece sobre 0 interno; e a terceira que acredita que terá supremacia de um ou outro de acordo com a ordem cronológica que de sua criação. Dessa forma, há a possibilidade de criação de ordenamentos jurídicos independentes pelos Estados $^{8}$.

A teoria dualista, tendo como precursor Hans Kelsen baseado no positivismo jurídico, teria os Estados sujeitando-se as normas internacionais, mas submete-as a rigoroso controle. Neste modelo os dos dois ordenamentos jurídicos são considerados distintos e independentes, onde 0 direito internacional para se tornar válido necessita de uma adequação para a sua recepção pelo direito interno. Assim a lei internacional apenas passa a fazer parte do ordenamento jurídico interno após a sua incorporação através de uma lei. Nesta teoria não se admite dois ou mais ordenamentos jurídicos iguais e independentes, pois deverá haver um mecanismo que as regule hierarquicamente. Desta forma, essa teoria não admite um processo de integração completo, pois submeter o Estado ao ordenamento internacional significaria ceder parte de sua soberania e independência a outro Estado ${ }^{9}$.

\section{DO CONCEITO DE SOBERANIA AO PROCESSO DE INTEGRAÇÃO}

Com o passar dos anos muitos Estados começaram a rescrever seu ordenamento jurídico para adequar seu direito interno as novas tendências mundiais, como regulamentações comerciais, políticas sociais, proliferação dos direitos humanos, mais também para a sua adequação aos processos

\footnotetext{
${ }^{8}$ LOCATELI, Cláudia C. Soberania e integração: possibilidades no âmbito do Mercosul.
} 
integracionistas. Aos poucos a teoria clássica de soberania foi sendo deixado de lado, assim como, os preconceitos ligados à teoria monista.

Segundo Cláudia Locateli o Estado pode adotar medidas internacionais sem perder a sua soberania, uma vez que a sua sujeição a normas internacionais traz benefícios para o Estado. Também acredita que isso não eliminará o conceito de soberania, que apesar de não ser absoluto, onde o poderes legislativos, jurisdicionais e administrativos ainda terão plenos poderes, apenas aceita ordenamentos jurídicos internacionais e supranacionais. Também ressalta que pode haver diversos tipos de soberania como a política, econômica, jurídica e cultural, onde poderá existir um processo de integração vinculado a um dessas áreas. Dessa forma, o conceito de soberania penas não permite uma integração a partir do imperialismo ou colonialismo.

\section{A SOBERANIA DOS ESTADOS-MEMBROS DO MERCOSUL}

Segundo Cláudia Locateli a Constituição de 1988 do Brasil traduz com conceito de soberania absoluta ao Brasil, não deixando margem para um processo de integração. Além de dar ênfase ao nacionalismo e a soberania nacional, ao menciona a sua delegação de poderes, elimina qualquer possibilidade de integração, pois não dá margem à delegação de poderes a um órgão supranacional. Não obstante, o Brasil se pauta sobre duas concepções fundamentais que é a nacionalista, vinculada ao conceito de soberania total, e os internacionalistas que acreditam em uma margem de flexibilização aos acontecimentos do cenário internacional.

Os adeptos as visões nacionalistas ainda estão vinculados ao conceito de guerras e a luta pela demarcação de terras, onde acreditam que a flexibilização de suas normas poderá gerar influencias das grandes potências e organismos internacionais. Também acreditam, mesmo que de forma remota, a possibilidade de retorno da dependência que existia quando o Brasil ainda era

\footnotetext{
${ }^{9}$ LOCATELI, Cláudia C. Soberania e integração: possibilidades no âmbito do Mercosul.
}

Revista Brasileira de Direito Internacional, Curitiba, v.2, n.2, jul./dez.2005 
colônia. Enfatizam a necessidade de manter seu poder de decisão e a eficácia do seu ordenamento jurídico sobre qualquer outro tipo de decisão externa.

A visão internacionalista acredita que utilizar-se do conceito de soberania total é negar a existência de relações entre os Estados e a sua cooperação. Para essa ótica o Brasil deve ser mais flexível com relação ao conceito de soberania e normas internacionais, a fim de facilitar o projeto de integração do Mercosul, consequentemente, ampliando o seu nível de bemestar.

Perante esses pressupostos, a doutrina brasileira procura encontrar uma via para poder se adequar às tendências mundiais, buscando uma maior flexibilidade e dinamismo do Estado. Em 1995 foi realizada uma tentativa de emenda constitucional, procurando tornar mais flexível à soberania em relação ao processo de integração do Mercosul. No entanto, a proposta foi rejeitada e ainda causou grandes discussões e preconceitos em relação à questão.

No que tange os outros Estados mercosulinos, a constituição argentina é mais flexível, pois permite que o Estado se vincule a projetos supranacionais. Também existe as correntes nacionalistas e internacionalistas, mas essa última é a mais forte, onde busca a criação de uma Corte Internacional de Justiça do Mercosul. Na reforma constitucional de 1994 a Argentina outorgou ao seu Congresso Nacional a competência de aprovar tratados de integração que deleguem competências a órgãos supranacionais, desde que eles se pautem sobre a reciprocidade, igualdade, respeitem os direitos humanos e a ordem democrática.

Dessa forma o ordenamento jurídico da Argentina permite a criação de órgãos supranacionais, permitindo até mesmo que essas leis sejam superiores ao ordenamento interno, desde que aprovadas por maioria absoluta na sua Câmara, quando se trata do processo de integração latino-americano. Sendo assim, esse ordenamento jurídico permite uma maior adequação do Estado as necessidades internacionais, a fim de galgar uma maior qualidade de vida para seus cidadãos.

A Constituição do Uruguai de 1967, da mesma forma que o Brasil, não permite a flexibilização da sua soberania em favor de um processo de 
integração. Regida pelo conceito monista procura manter o conceito clássico de soberania a fim de se proteger em relação às intervenções externas. Dessa forma, mesmo frente à possibilidade de integração, para impulsionar o seu desenvolvimento, com uma ênfase no processo de integração latinoamericano, a constituição uruguaia não permite a sua adequação para criar um ordenamento jurídico que seja capaz de concretizar o projeto de integração do Mercosul.

A exemplo da Argentina, o Paraguai ressalta o mundo em constante interdependência onde já não há mais espaços para critérios nacionalistas. Expõem, na sua carta constitucional de 1992, a possibilidade de ceder ou transferir parte de sua soberania em favor de um organismo de integração. No entanto, condiciona esta questão a aprovação por maioria absoluta em suas Câmaras e Congresso. Também há claras manifestações dualistas, e o desejo de concretizar o projeto de integração do Cone Sul como a criação de órgãos supranacionais, sobre tudo, a criação de um Tribunal para julgar os litígios entre Estados-Membros e os nacionais.

Como podemos perceber não há uma coesão nas estruturas jurídicas e institucionais dos Estados-Membros do Mercosul, que permita uma relação mais eqüinime entre os Estados para ampliar o processo de integração. Faz-se necessário um trabalho conjunto para buscar uma harmonização das legislações internas e criar órgãos supranacionais para que se tenha êxito o processo de constituição do Mercosul.

\section{EVOLUÇÃO DO PROCESSO DE SOLUÇÃO DE CONTROVERSAS DO MERCOSUL}

Para entendermos o processo de evolução do sistema de solução de controversas do Mercosul, estaremos analisando o sistema de solução de controversas a partir dos seguintes tratados:

Revista Brasileira de Direito Internacional, Curitiba, v.2, n.2, jul./dez.2005 


\subsection{TRATADO DE ASSUNÇÃO}

O sistema de solução de controversas no Tratado de Assunção trata da matéria apenas de forma embrionários, e atenta-se às controversas em relação ao seu objetivo. Quanto ao mecanismo de solução, as partes devem primeiro procurar solucionar suas divergências através de negociações diretas, com a utilização de especialistas do Grupo do Mercado Comum, e somente se necessário e se não houver solução, submeter o litígio à apreciação do Concelho Mercado Comum.

Dentro de cento e vinte dias da vigência do tratado os EstadosMembros deveriam apresentar uma proposta para a criação de um Sistema de Solução de Controversas que vigoraria durante o processo de transição, até que fosse adotado um Sistema Permanente de Solução de Controversas. Em 17 de dezembro de 1991 foi convencionado o Sistema de Solução de Controversas que vigoraria no período de transição e que recebeu o nome de Protocolo de Brasília para Solução de Controversas.

\subsection{PROTOCOLO DE BRASÍLIA}

O Protocolo de Brasília foi aprovado pelo congresso brasileiro em dezembro de 1992, vindo a ter vigência a partir de setembro de 1993. Este documento é um complemento de 36 artigos ao Tratado de Assunção. Este também permite a reclamação de particulares (pessoas físicas ou jurídicas) que se vem "afetados por medidas legais ou administrativas de efeito restritivo, discriminatório ou de concorrência desleal, em violação ao Tratado de Assunção". ${ }^{10}$

\footnotetext{
${ }^{10}$ CASELLA, Paulo. Borba. Contratos internacionais e direito econômico no Mercosul após o termino do período de transição, 1996, pg. 351.
}

Revista Brasileira de Direito Internacional, Curitiba, v.2, n.2, jul./dez.2005 


\subsubsection{Sistema aplicável aos Estados-Membros}

O sistema de solução de controversas entre os Estados-Membros no Protocolo de Brasília ocorrer através da arbitragem. No entanto, este apenas entra em operação após o fim das tentativas de solução através das negociações diretas com o apoio do Grupo do Mercado Comum, que não poderá se estender por mais de trinta dias.

O sistema funciona com um tribunal ad hoc, onde a jurisdição empregada, os Estados-Membros declararam reconhecer as controversas relacionadas com o Protocolo de Brasília, sendo o direito aplicável o Tratado de Assunção, além dos acordos celebrados no seu âmbito, decisões do Concelho do Mercado Comum e resoluções do Grupo do Mercado Comum. Será excluída a utilização de eqüidade se as partes assim desejarem.

O laudo arbitral deverá ser adotado por maioria e deverá ser fundamentado. No entanto, a votação será confidencial, onde não há a necessidade de fundamentação do voto desistente. O laudo proferido é inapelável e é de cumprimento obrigatório pelo Estado-Membro no prazo de quinze dias, ou outro se estipulado, a contar da notificação do laudo. Caso o laudo não seja cumprido o Estado-Membro prejudicado poderá aplicar medidas compensarias.

\subsubsection{Sistema Aplicável Entre Particulares e Estados-Membros}

A possibilidade de reclamações de particulares (pessoas físicas ou jurídicas) podem ocorrem com relação aos seguintes temas: que venha a ser afetados por medidas legais ou administrativas de efeito restritivo, de efeito discriminatório ou de concorrência desleal, violação dos Tratados e acordos celebrados no âmbito do bloco, assim como, pelas decisões do Conselho do Mercado Comum e resoluções do Grupo do Mercado Comum.

Diferentemente do processo entre Estados, a reclamatória será formalizada junto à Seção Nacional do Grupo de Mercado Comum do EstadoMembro de residência do reclamante. Em primeiro momento poderá haver a 
busca de uma solução através de negociações na própria a Seção Nacional do Grupo de Mercado Comum do Estado-Membro e o particular. Caso não haja solução a reclamatória será submetida ao Grupo de Mercado Comum, que reunirá peritos para dar um parecer a respeito do caso. Caso não haja uma solução o Estado-Membro interessado poderá solicitar a abertura de processo arbitral.

O laudo arbitral é um recurso comum no direito internacional e é muito comum a sua utilização para resolver litígios entre Estados como entre particulares. No entanto, no caso do Protocolo de Brasília o laudo arbitral tem caracter de cláusula compromissória, o que obriga os Estados-Membros a se submeterem à solução arbitral quaisquer que sejam as controversas no futuro, onde se reconhece a jurisdição do tribunal arbitral sobre os litígios.

A submissão das soluções de controversas através de laudo arbitral é mais comum nos acordos de comércio internacional. Geralmente somente quando há a previsibilidade de ocorrer um litígio e como ele irá ocorrer é que se estabelece a forma arbitral para a solução e o foro para tal. Não obstante 0 Protocolo de Brasília, em seus artigos 8 e 11 dispensa a celebração de um compromisso arbitral específico para a solução de uma controversa entre os Estados-Membros.

Segundo Paulo Casella essas medidas são adotadas pelo Protocolo de Brasília a fim de tornar mais efetivas as disposições do tratado, tentando assim se desvincular da fórmula adotada nos acordos meramente econômicos. Também procura colocar regras quanto à forma de solução de controvérsias, a fim de evitar as lacunas deixadas em muitos acordos internacionais. No entanto, o processo de solução de controversas a partir do Protocolo de Brasília padece de vício, pois condiciona a busca do interesse, supostamente lesado, do particular em favor do interesse do Estado-Membro, uma vez que esse é o único que pode buscar a arbitragem.

Revista Brasileira de Direito Internacional, Curitiba, v.2, n.2, jul./dez.2005 


\subsection{PROTOCOLO DE OURO PRETO}

As discussões que nortearam o momento em que ele ocorreu, precedeu a institucionalização do Mercosul, onde era reclamado um órgão institucional incumbido da solução de controversas. "O problema surge, porém no momento em que a criação de órgãos comunitários exige algum tipo de restrição da soberania dos Estados algo, aliás, que se choca com o princípio da soberania absoluta, ardentemente defendida pelos Estados latinoamericanos". ${ }^{11}$

Para um melhor funcionamento o Mercosul deveria ter um órgão judiciário superior, como uma Corte de Justiça, que permitisse controlar a obediência das regras jurisdicionais e punisse os transgressores, tudo em favor do pleno funcionamento do Mercado Comum. No entanto, esse ideal não foi alcançado. Manteve-se o Protocolo de Brasília e demais tratados e acordos para o sistema de solução de controversas. Segundo Paulo Casella, ainda não tinha sido considerado o momento de criar um órgão superior de justiça, que até então tinha sido considerado dispensável, seja para evitar a estratificação de organismos, seja para evitar confrontos intra-institucionais com a criação desse órgão.

Com relação ao processo de solução de controversas o Protocolo de Brasília trouxe, em seu anexo, apenas os procedimentos que devem ser seguidos para solucionar o litígio via negociação, o processo de formalização de uma reclamatória e qual o procedimento que deverá ser seguido para que se tenha a solução do litígio através da arbitragem.

No entanto, o Protocolo de Ouro Preto parece, em seu Regulamento Geral, ter restringindo o acesso do Estado ao recurso de arbitragem, quando o Estado reclamado não der cumprimento as resoluções da Comissão de Comércio do Mercosul ou do Grupo de Mercado Comum. Também no caso da Comissão de Comércio do Mercosul ou do Grupo de Mercado Comum entender que há improcedência na reclamação de um Estado-Membro, este não terá direito a recorrer à arbitragem. Outra questão de importância é que

\footnotetext{
${ }^{11}$ BRANCO, pp. 165
}

Revista Brasileira de Direito Internacional, Curitiba, v.2, n.2, jul./dez.2005 
mais uma vez as reclamações de particulares (pessoas físicas ou jurídicas) ficaram a mercê de prévio amparo do Grupo do Mercado Comum. Mesmo que o Estado-Membro realmente esteja violando as leis o particular não poderá reclamar aos tribunais nacionais, pois esse direito foi suprimido pelo Protocolo de Brasília.

\subsection{PROTOCOLO DE OLIVOS}

O Protocolo de Olivos de 18 de fevereiro de 2002 é o ultimo documento emitido pelo Mercosul em relação ao sistema de solução de controversas. Ele traz a institucionalização do Mercosul com a criação de um procedimento permanente para a solução de controversas no lugar de um sistema ad hoc por via arbitral, o que contribui para a criação de uma jurisprudência para o Mercosul. No entanto ele ainda não define as estruturas definitivas do bloco. Estas apenas serão estabelecidas quando for possível estabelecer a integração e a liberalização dos quatros fatores de produção ${ }^{12}$. Este protocolo esboça a maturidade dos Estados-Membros para com o processo de integração, para as transformações do bloco, e adequação as novas tendências da globalização.

Dentre as transformações podemos encontrar a faculdade da solução de controversas relacionadas ao comercio serem resolvidas com o foro no Mercosul, OMC ou outra forma preferência, como esboça o protocolo:

\footnotetext{
“[...] As controvérsias compreendidas no âmbito de aplicação do presente Protocolo que possam também ser submetidas ao sistema de solução de controvérsias da Organização Mundial do Comércio ou de outros esquemas preferenciais de comércio de que sejam parte individualmente os Estados partes do Mercosul, poderão submeter-se a um ou a outro foro, à escolha da parte demandante. Sem prejuízo disse, as partes nas controvérsias poderão, de comum acordo, definir o foro. Uma vez iniciado um procedimento de solução de controvérsias de acordo com o parágrafo anterior, nenhuma das partes poderá recorrer a mecanismos de solução de controvérsias estabelecidos nos outros foros com relação a um mesmo objetivo, definidos nos termos do art. 14 deste Protocolo". $13^{3}$
}

\footnotetext{
${ }^{12}$ Os quatros fatores de produção são bens, pessoas, serviços e capitais.

${ }^{13}$ Protocolo de Olivos, Olivos 2002, Art. 1으, incisos $2^{\circ}$ e $3^{\circ}$
} 
Apesar das alterações estabelecidas pelo Protocolo de Olivos, podemos dizer que não foi muito favorável ao Mercosul, pois ele permite que se deixe transparente as divergências que ocorrem no bloco ${ }^{14}$. No entanto, permite que uma controvérsia que não tenha sido resolvido no processo de negociação possa ir diretamente a solução judicial, sem que seja necessária sujeitá-la ao Grupo do Mercado Comum. Outra questão é a utilização de um mesmo arbitro para mais de um Estado, quando estes mantêm uma mesma posição em relação a uma controvérsia.

Quando um Estado se sentir lesado poderá, antes da decisão judicial, tomar medidas provisórias para evitar maiores danos. Neste caso o Tribunal Arbitral Ad Hoc solicitará que seja fundamentado o seu pedido da parte lesada, onde a manutenção da dada situação poderá causar danos graves e/ou irreparáveis. Neste caso o Tribunal Arbitral ditará as medidas a serem tomadas. Se o caso for passível de recurso de revisão o Tribunal Permanente de Revisão colocará o tema na sua primeira reunião, onde decidirá pela manutenção ou extinção da medida provisória. Até que saia o novo laudo, a medida provisória estabelecida deve ser cumprida ${ }^{15}$. Se o laudo arbitral não for cumprido, dentro do prazo de um ano, o Estado lesado poderá adotar medidas compensatórias para forçar o cumprimento do laudo, onde o tribunal poderá intervir a qualquer momento, desde que seja solicitado ${ }^{16}$.

Apesar das grandes alterações no sistema de solução de controvérsias os particulares ainda continuam sem ter acesso ao tribunal, salvo nas questões de não cumprimentos dos temas acordados entre os Estados-Membros.

O Tribunal Permanente de Recurso foi oficialmente criado em 13 de agosto de 2004, na cidade de Assunção, Paraguai. Tendo referência a solução de controvérsias aos moldes da OMC, procurou criar um sistema de consultas para os Estados-Membros, com um corpo de especialistas e peritos ${ }^{17}$. Estes

\footnotetext{
${ }_{14}^{14}$ GOMES, pp. 85.

${ }^{15}$ Protocolo de Olivos, Art. 15, incisos 1‥

${ }^{16}$ Idem, Art. 34.

As medidas podem ser pelo viés econômico, como barreias as importações.

${ }^{17}$ Somente pode emitir opiniões consultivas junto ao Tribunal Permanente de Revisão, são os órgãos de capacidade decisória do Mercosul, assim como, os Tribunais Superiores dos Estados Membros, que tenham jurisdição nacional. As opiniões emitidas pelo ao Tribunal Permanente de Revisão não possuem caráter vinculante ou de cumprimento obrigatório.
}

Revista Brasileira de Direito Internacional, Curitiba, v.2, n.2, jul./dez.2005 
devem ser utilizados quando as negociações direitas não surtirem efeito. Desta forma também procura corrigir eventuais assimetrias entre os membros e, sobre tudo, tornar as relações destes mais eqünemes.

Em geral o sistema de solução de controvérsias, por via arbitral ad hoc, não é cabível de apelação ou revisão. No entanto, no Mercosul é possível esse recurso junto ao Tribunal Permanente de Revisão. Por um lado isso diminui o prestígio do sistema arbitral que é muito utilizado na esfera internacional, por outro, a manutenção desse sistema é necessária para a formação de uma jurisprudência, no sentido lato, que contribuirá para o crescimento institucional do Mercosul.

\section{CONSIDERAÇÕES FINAIS}

O processo de integração do Mercosul vem para se adequar à nova tendência mundial que visa uma maior participação no cenário internacional a partir da formação de blocos econômicos. Não obstante, para que o relacionamento em bloco possa trazer benefícios simétricos se faz necessário à criação de um eficiente sistema de solução de controvérsias. Apesar do Mercosul ter tido evoluções, ainda necessita de aperfeiçoamento.

Apesar da tendência atual de integração, a questão de soberania ainda é um tema sensível, quando o interesse nacional é suprimido pelo interesse do bloco. Com os Protocolos de Assunção e Ouro Preto o sistema de solução de controvérsias, por via arbitral, não surtiu grandes efeitos. Também não contribuía para a criação de uma jurisprudência e um corpo de juízes especializados e permanente, uma vez que o sistema era ad hoc.

A institucionalização do Mercosul com o Protocolo de Olivos permitiu uma maior regulamentação das relações entre os Estados Membros. Não obstante, o Mercosul ainda carece de órgãos supranacionais. A questão de soberania sempre é retomada, como observamos nas decisões expedidas pelo Mercosul, as quais não possuem aplicabilidade direta, sendo necessário a sua aprovação nos congressos nacionais e a internalização dos acordos.

Revista Brasileira de Direito Internacional, Curitiba, v.2, n.2, jul./dez.2005 
O fato de particulares não terem acesso ao sistema de solução de controvérsias, salvo quanto a não aplicação dos acordos pelos Estados, contribuí para enfraquecer o bloco, visto que estes não possuem uma participação efetiva no processo de integração. Caso um particular venha a utilizar o sistema arbitral, os seus custo se tornará viável apenas para aqueles de alto poder aquisitivo, além de estes ficarem a mercê da vontade do seu Estado para enviar a sua reclamação até os órgãos mercosulinos.

Por fim, não podemos pensar em um Mercado Comum onde os Estados possuem leis distintas. A pesar da criação do Tribunal Permanente contribuir para melhorar o relacionamento dos seus membros, a sua real efetividade apenas ocorrerá com a união completa dos fatores de produção.

\section{REFERÊNCIAS}

ALMEIDA, Paulo Roberto de. Mercosul e Alca na perspectiva do Brasil: uma avaliação política sobre possíveis estratégias de atuação - O Brasil e a Alca: seminário. Brasília, IPRI, 2002, pg. 97-110.

BRANCO, Luizella Giardino G. Sistema de solução de controvérsias no Mercosul. São Paulo: LTr, 1997.

CASELLA, Paulo. Borba. (coordenador.). Contratos internacionais e direito econômico no Mercosul após o termino do período de transição. São Paulo: LTr, 1996.

FERLAN, Fernando de Magalhães. Integração e soberania: o Brasil e 0 Mercosul. São Paulo: Aduaneiras, 2004.

GABRIEL, Amélia R. M. O conflito entre tratado e direito interno face ao ordenamento jurídico brasileiro e outras questões conexas [Online]. Jus Navigandi, Teresina, a. 8, n. 390, 1 ago. 2004. Disponível em: http://jus2.uol.com.br/doutrina/texto.asp?id=5505. Acesso em: 12 out. 2005.

GOMES, Eduardo B. Protocolo de Olivos: alterações no sistema de solução de controvérsias do Mercosul e perspectivas. Revista de Direito Constitucional e Internacional, n.․ 42, p. 79-88, 2003.

HOBBES, Thomas. Leviatã ou matérias, forma e poder de um Estado eclesiástico e civil. Coleção a obra-prima de casa autor, série ouro. São Paulo, Martin Claret, 2002. 
LOCATELI, Cláudia C. Soberania e integração: possibilidades no âmbito do Mercosul [Online]. Disponível em Disponível em:

http://jus2.uol.com.br/doutrina/texto.asp?id=2486. Acesso em: 30/09/2005.

Protocolo de Olivos [Online]. Olivos, 2002. Disponível em

http://www.mercosul.gov.br/textos/default.asp?Key=182. Acesso em

05/10/2005.

Protocolo de Ouro Preto [Online]. Ouro Preto, 1994. Disponível em http://www.mercosul.gov.br/textos/default.asp?Key=17. Acesso em 05/10/2005.

Tratado de Assunção [Online]: Assunção, 1991. Disponível em http://www.mercosul.gov.br/textos/default.asp?Key=45. Acesso em 05/10/2005.

Revista Brasileira de Direito Internacional, Curitiba, v.2, n.2, jul./dez.2005 